\title{
Energy analysis of a CHP plant with internal combustion engines, for a district heating system, based on the information from the annual database
}

\author{
Gabriel Mărcuș ${ }^{1}$, Vlad Iordache $^{1}$, Florin Iordache $^{1}$, and Anica Ilie $^{1}$ \\ ${ }^{1}$ CAMBI Research Center, Technical University of Civil Engineering of Bucharest, Romania
}

\begin{abstract}
Building a model for consumption, production and efficiency of a combined heat and power (CHP) system can bring important data for planning and management activity of such a technological system. The results of this study will show the overall efficiency of a real cogeneration plant over a year. The study is based on the information from the daily database of an economic operator, during 2012. The CHP plant, having reciprocating internal combustion engines (RICE) as prime movers, provides the thermal energy to the district heating system of a city from Romania with 129,368 habitants. RICE are operating in simultaneous mode or in partial load. The numerical model reveals the behavior of the daily thermal, electrical and global efficiency, accordingly to the partial load. The model was applied in both calculation assumptions: using the lower heating value and the higher heating value of the natural gas. A statistical analysis of efficiencies of the CHP plant was made. Was performed the statistical analysis of the database efficiency (also called real efficiency) with the global efficiency calculated by the model (also called modelled efficiency). Linear and multiple regression equations explain the variance of the real efficiency and of the modelled global efficiency.
\end{abstract}

\section{Introduction}

Cogeneration systems involve the combined production of electricity and heat for space heating and hot water, using a single source of fuel. Cogeneration technologies comprise several subsystems and equipment with multiple interconnection capabilities. In the case of classical systems, the efficiency of separate heat and electricity production is, accordingly to the literature, about $58 \%$. In the case of cogeneration the efficiency reaches $85 \%$ [1]. Cogeneration technology based on (RICE) enjoys wider appreciation and spreads among investors' decisions at the time of implementing the method of producing the two forms of energy, heat and power.

In a previous study [2], the CHP plant efficiency was compared for three different operation modes.

This study used:

- the equation found by Sanaye S. et al. [3] regarding the thermal efficiency at partial load,

- ASHRAE equation 2008 [4] regarding the variation of the efficiency of the electric generators and

- the method of calculating the energy requirements and the system efficiency in SR EN 15316 [5], [6].

The conclusion was that the simultaneous operating mode of engines at the same load without the boiler intervention is the most advantageous. Simultaneous mode of operation has led to: obtaining maximum individual thermal efficiency on wider ranges of load values, observing shorter maintenance periods due to the shorter periods of use of the boiler and getting $40 \%$ more

\footnotetext{
* Corresponding author: marcus_gabriel@yahoo.com
}

useful electrical power compared to the other modes of operation.

In order to continue the scientific research of the processes occurring in a CHP plant with RICE, information were obtained and analysed from an economic operator database. This economic operator supplies the thermal energy to a city in Romania with 129,368 inhabitants (year 2012). The numerical model built for the cogeneration plant, based on the daily data information had the ultimate goal the comparison between the daily global efficiency calculated with previously mentioned formulas, named 'modelled efficiency' in the present paper, and the daily efficiency from the database, named 'real efficiency' in the present paper. The daily thermal, electrical and global values of efficiency for the whole of 2012 are processed and analysed statistically in relation to the partial load, PL, accordingly to the daily operating hours recorded in the database. Variations in efficiency trends were observed and linear regression equations have been developed for thermal, electrical and global efficiency. The slope of regression line was found and the intercept for $\mathrm{PL}=50 \%$ (the minimum partial load). The present study compares the modelled efficiency values with the real efficiency values from two perspectives: the calculation using lower heating value and the calculation using higher heating value. At the end of this work is elaborated a multiple regression equation for the real efficiency which takes into account the partial load and the modelled efficiency.

The method described in this paper makes evaluation possible to estimate precisely what global efficiency is 
really obtained in a cogeneration plant similar to the plant under consideration. The method can be extrapolated, under certain conditions, to systems made up of several RICE, with the same technical characteristics (the same manufacturer). The numerical model can be applied to other types of RICE-s by introducing in the model both: the corresponding technical specifications and the production and consumption parameters recorded during periods of operation, for these new types of equipment.
Note that for other types of engines, the model cannot be applied using the same database information used in the current paper simply by changing the technical specification entry; it requires new recorded data and a new experiment with a time step that may be different from the daily one. The conclusions will be more accurate as the registration time step will be reduced.

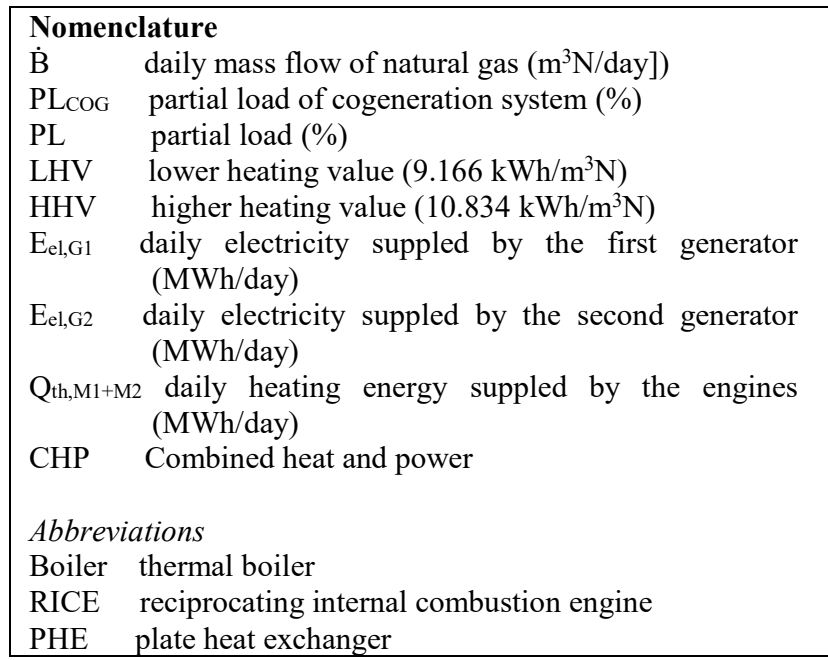

\section{Technological scheme}

The cogeneration system analysed, Fig. 1, has two RICEs Jenbacher JMS 620 GS-NL equipped with electric generators, with a nominal power of $3119 \mathrm{~kW}$, according to ISO standard (ICFN), used as prime movers for the production of heat and power. The peak source used consists of two hot water boilers, $35 \mathrm{MW}$ International Loos. For the domestic hot water recirculation system, in the summer when there is no demand for heating load, a hot water boiler of $11.6 \mathrm{MW}$ is used.

\begin{tabular}{|c|c|c|}
\hline \multirow{2}{*}{\multicolumn{3}{|c|}{$\mathrm{M}_{1} \quad$ first reciprocating internal combustion engine }} \\
\hline & & \\
\hline $\mathrm{M}_{2}$ & second reciprocating internal combustion eng & \\
\hline $\mathrm{G}_{1}$ & first electrical generator & \\
\hline $\mathrm{G}_{2}$ & second electrical generator & \\
\hline \multicolumn{3}{|c|}{ Greek letters } \\
\hline$\eta_{\mathrm{elCOG}}$ & modelled electrical efficiency (\%) & \\
\hline$\eta_{\text {elCOG }}^{2 E}$ & $\begin{array}{l}\text { modelled electrical efficiency without electr } \\
\text { outliers values }(\%)\end{array}$ & \\
\hline$\eta_{\text {thCOG }}$ & modelled thermal efficiency (\%) & \\
\hline$\eta_{\text {thCOG }}^{2 \mathrm{E}}$ & $\begin{array}{l}\text { modelled thermal efficiency } \\
\text { outliers values }(\%)\end{array}$ & thermal \\
\hline$\eta_{\text {global }}$ & modelled global efficiency $(\%)$ & \\
\hline$\eta_{\text {global }}^{2 \mathrm{E}}$ & $\begin{array}{l}\text { modelled global efficiency without } \\
\text { outliers values }(\%)\end{array}$ & global \\
\hline$\eta_{\mathrm{BDB}}$ & real efficiency recorded in the database $(\%)$ & \\
\hline
\end{tabular}

RICE-s and hot water boilers are connected to plate heat exchangers for heat transmission to the district heating grid. The water supply for the primary circuits or for the addition water in case of losses pre-treated in a water softening/degassing module by reverse osmosis.

The fuel for the boiler burners and for the combustion chambers of the engines is the natural gas from the Prahova county basin with the lower heating value LHV $=9,17 \mathrm{kWh} / \mathrm{Nm}^{3}$.

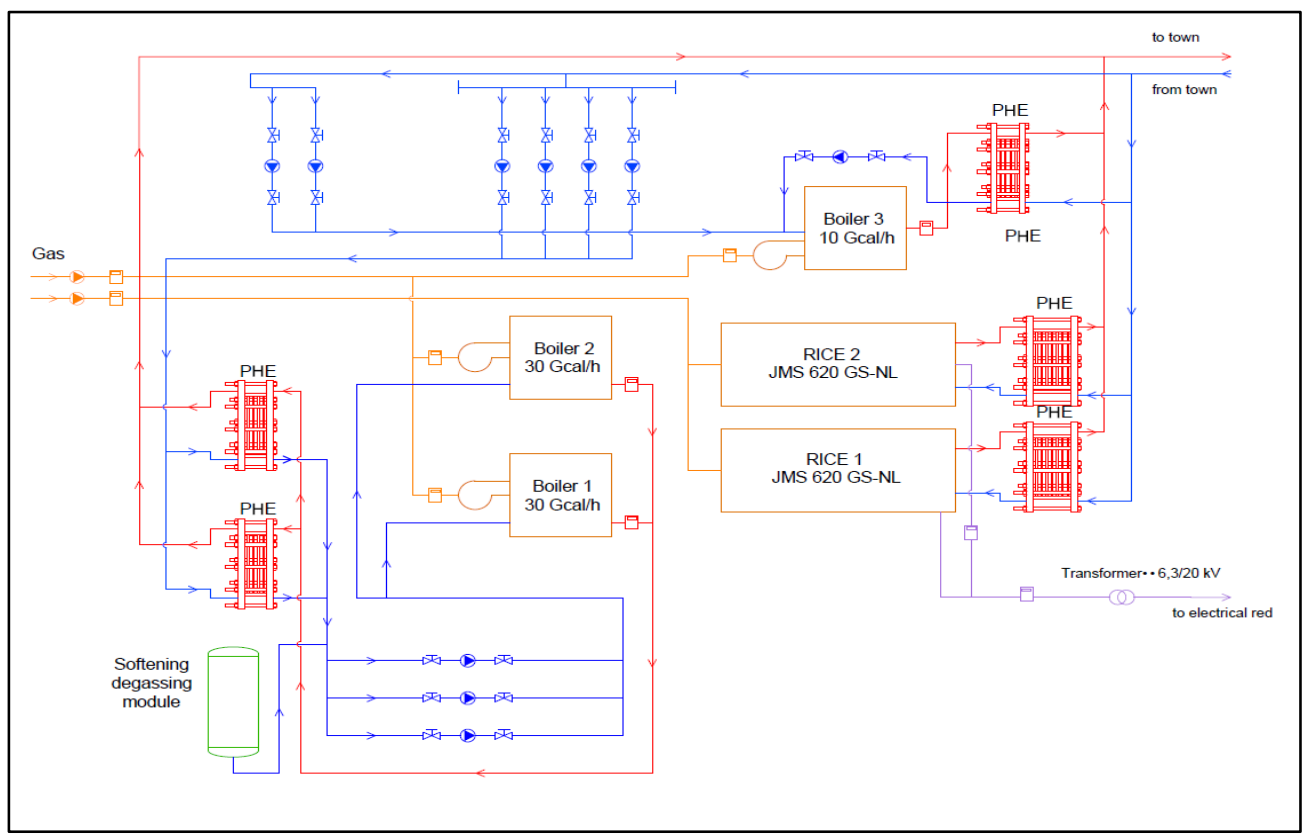

Fig. 1. Technological scheme of CHP. 


\section{Database}

The daily recorded data for year 2012 consist in: the operating hours of each of two engines, the daily and hourly consumption of natural gas, the daily and hourly electricity supply produced by each of electrical generator, the daily and hourly heat supply - cumulative value on the two internal combustion engines - and the daily global efficiency of the system recorded by the operator. Regarding the daily global efficiency recorded data along the months of 2012, it can be observed that they have higher values during the winter months (October, November, December, January - around $75 \% \div 79 \%$ ) and smaller values during the summer months (July, August,
September - between $70 \% \div 73 \%$ ). During the year 2012 there have been several hours when one of the cogeneration modules (thermal engine + electrical generator + turbo charger) was not operational due to the maintenance interventions.

The natural gas consumption of the cogeneration system ranges between a minimum of $17898 \mathrm{~m}^{3} /$ day on January 4, 2012, corresponding to a period when only one engine was operational (for the first 7 days of January 2012) and a maximum of $39373 \mathrm{~m}^{3} /$ day on October 27 , 2012 corresponding to a period when both engines were operational (Fig. 2).

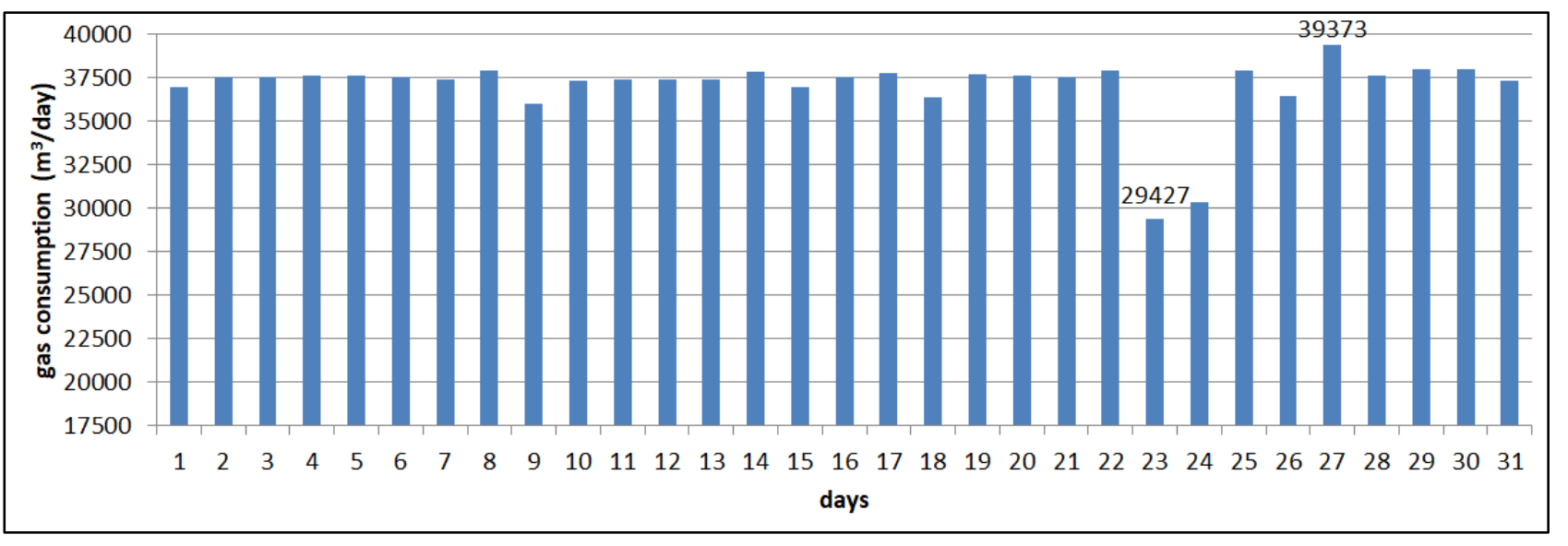

Fig. 2. Consumption of natural gas, October $2012, \mathrm{~m}^{3} /$ day.

\section{Numerical model}

The initial numerical model [2] configured in operating mode 3 , which means simultaneous operation at the same loads without the intervention of the boiler, is applied to the cogeneration system engines. The model, Fig. 3, uses the daily time step during the year 2012. From the database were taken the measured data for: the cumulated heat output of the two engines (M1 and M2) and the daily operating hours of each engine, the individual production of the electric energy of each engine in and the daily global efficiency, named as real efficiency.

In simultaneous operation mode, M1 and M2 divide heat production equally during daytime running hours. At the division of heat production we had introduced the condition of the nominal thermal output of the engine in the data sheet $-3070 \mathrm{~kW}$. In the months of October, November and December the thermal boilers operates to provide the heating peak load. For each engine was calculated in the model, after dividing the cumulative heat output: the partial load $\left(\mathrm{PL}_{\mathrm{COG}}\right)$, the individual thermal and electrical supply at partial load and the useful energies of entire system: thermal, electrical, total, the lost energy and the consumed fuel energy by the cogeneration system. For the fuel energy input, the model was tested in both possible situations: first - considering the lower heating value, $\mathrm{LHV}=9,1667 \mathrm{kWh} / \mathrm{Nm}^{3}$, in which case the differences from the real efficiency were higher between $4.34 \%$ and $5.40 \%$ and second - considering higher heating value, $\mathrm{HHV}=10,8347 \mathrm{kWh} / \mathrm{Nm}^{3}$, in which case the value differences from the real efficiency were lower by $5.96 \%$ to $9.58 \%$, Fig. 4. The first case considered was closer to reality and was adopted to lead this analysis. Finally, the total thermal efficiency and was closer to reality and was adopted to lead this analysis. Finally, the total thermal efficiency and the global (thermal + electric) efficiency of CHP system have been calculated.

The initial numerical model [2] was built for MWM internal combustion engines with a nominal thermal output of $1675 \mathrm{~kW}$. Accordingly to the analysis performed on the MWM engines, the partial load interval (PL) when the maximum thermal efficiency is reached ranges from $85.77 \%$ to $91.47 \%$. It has been a matter of checking the optimum PL range for the M1 and M2 engines of actual plant, with the thermal output of 3070 $\mathrm{kW}$. First, the technical data of the new engines were introduced in the model (the nominal thermal output and the nominal electrical power). The maximum thermal efficiency was $42.96 \%$ on the new partial load intervals, respectively $85.31 \%-91.95 \%$ PL for M1, and $85.31 \%$ 91.97\% PL for M2. It can be seen that the higher the engines nominal power the wider the maximum thermal efficiency range. 


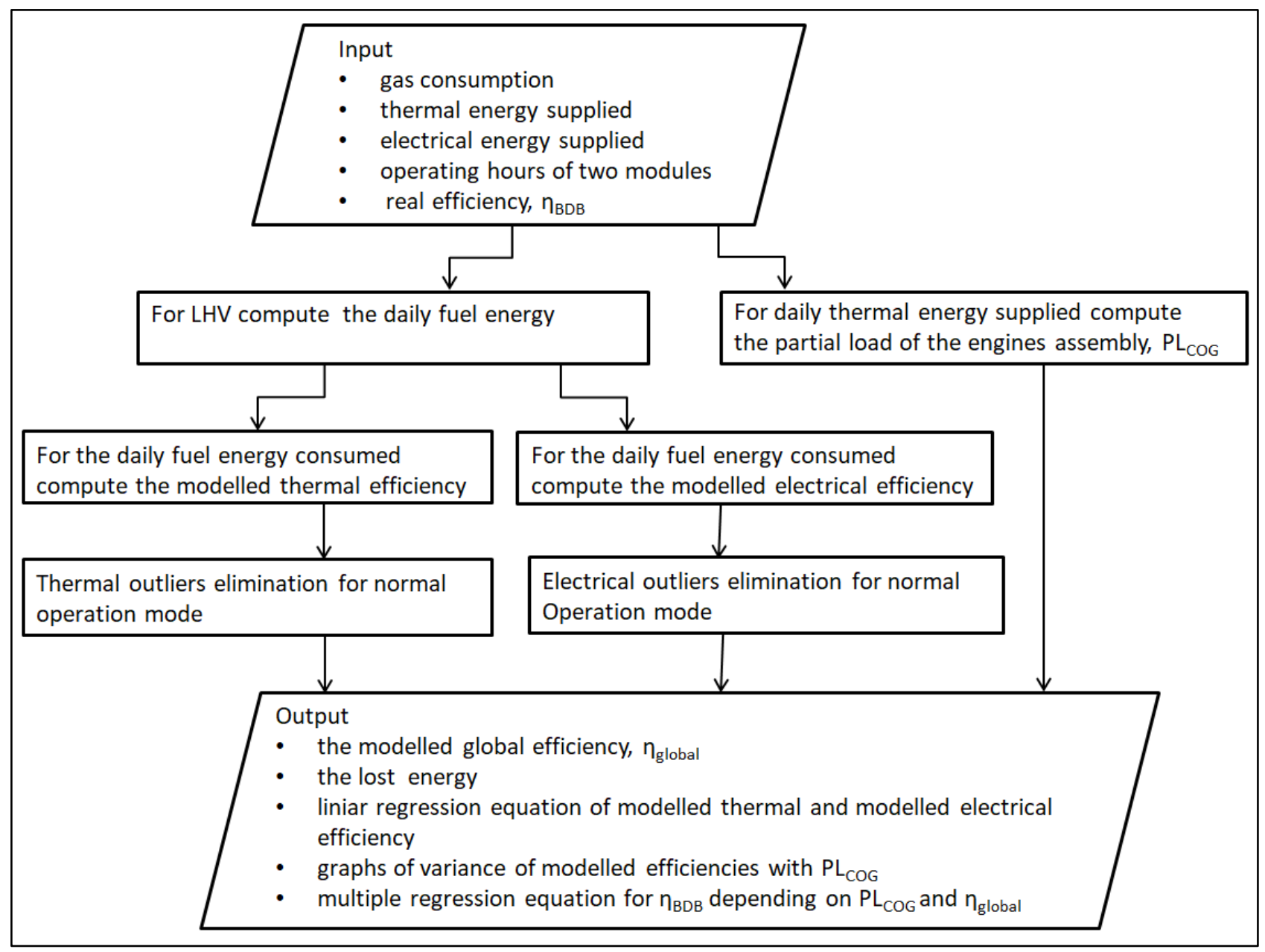

Fig. 3. The model of energy analysis of database.

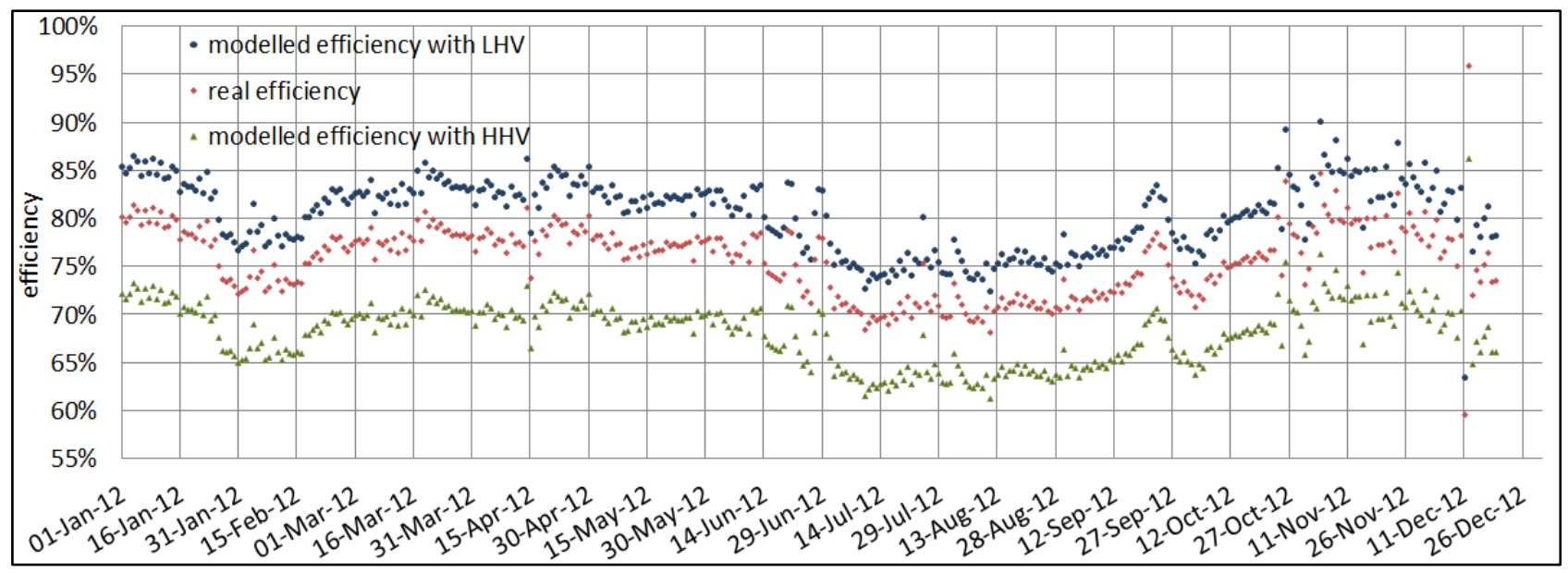

Fig. 4. Modelled efficiency and real efficiency with LHV and HHV.

A calculation of the operating time at the maximum thermal efficiency was performed accordingly to the optimal operating interval of partial load $(85.31 \%$ $91.97 \%$ PL). The highest number of days (17 days) at the maximum thermal efficiency was in February 2012.
The frequency of occurrence of the global daily modelled efficiency (in day's number) is shown in Fig. 5. The values of global daily modelled efficiency ranged between $60 \%$ and $100 \%$ have been investigated, with a 5 percent step. The most frequent occurrence of $85 \%$ efficiency is observed in 185 days of the year. The 
analysis of daily global efficiency figures has led to the observation of a wrong recording for two consequently days (more than $100 \%$ global efficiency).

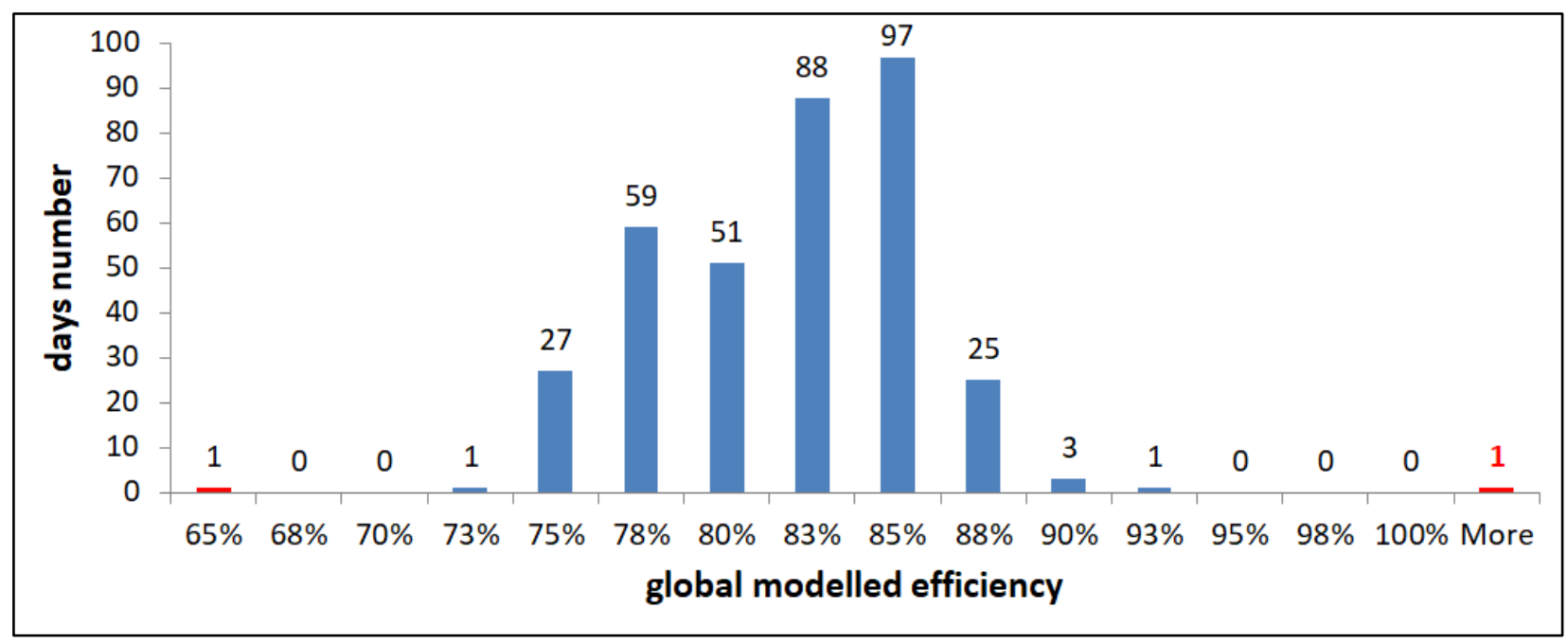

Fig. 5. Frequency of daily global modelled efficiency, 2012.

\section{Energy analysis}

The energy analysis has proposed the observation of the cloud of points, the identification of the outliers values and the highlighting of the trends of variation of the modelled efficiencies.

Based on the primary visual analysis, it is observed that the modelled thermal efficiency, $\eta_{\text {thCOG, }}$ exhibits an increasing variation with the partial load of the engines assembly, PLCOG, Fig. 6, a.

At the same partial operation load, several values of the modelled thermal efficiency are recorded on different days of the year with very small differences between them (vertical points). At the same partial load, the calculated daily thermal efficiency may vary to a maximum of 4 percent.

From the diagram of the normal distribution of the thermal modelled efficiency, the points that appeared dispersed (the red points) called 'thermal outliers values' will be removed. The outliers values were mainly recorded during the days when one of engines did not work the whole day or during the maintenance periods. Also will be removed the one day wrong recording data (more than 100\% thermal efficiency).

The variation of the modelled electrical efficiency, $\eta_{\mathrm{elCOG}}$, depending on the PL of engines assembly, PL $\mathrm{COG}_{\mathrm{CO}}$, Fig. 6, b., is almost constant and it can be said that partial load operation does not influence its variation. At 50\% PL (the minimum operating load), the electrical modelled efficiency in the model is $41.72 \%$, a very small decrease of $1.88 \%$ from the maximum electrical modelled efficiency $(43.60 \%)$.

In this case, also the observation is valid: at the same operating PL several values of the electrical efficiency, with small differences between them (vertically close points), are recorded. From the diagram of the normal distribution of the electrical modelled efficiency, the points that appeared dispersed (the red points) called 'electrical outliers values' will be removed. The outliers were mainly values recorded during the days when one of engines did not work the whole day or during the maintenance periods. Also will be removed the one day wrong recording data (more than $100 \%$ electrical efficiency).

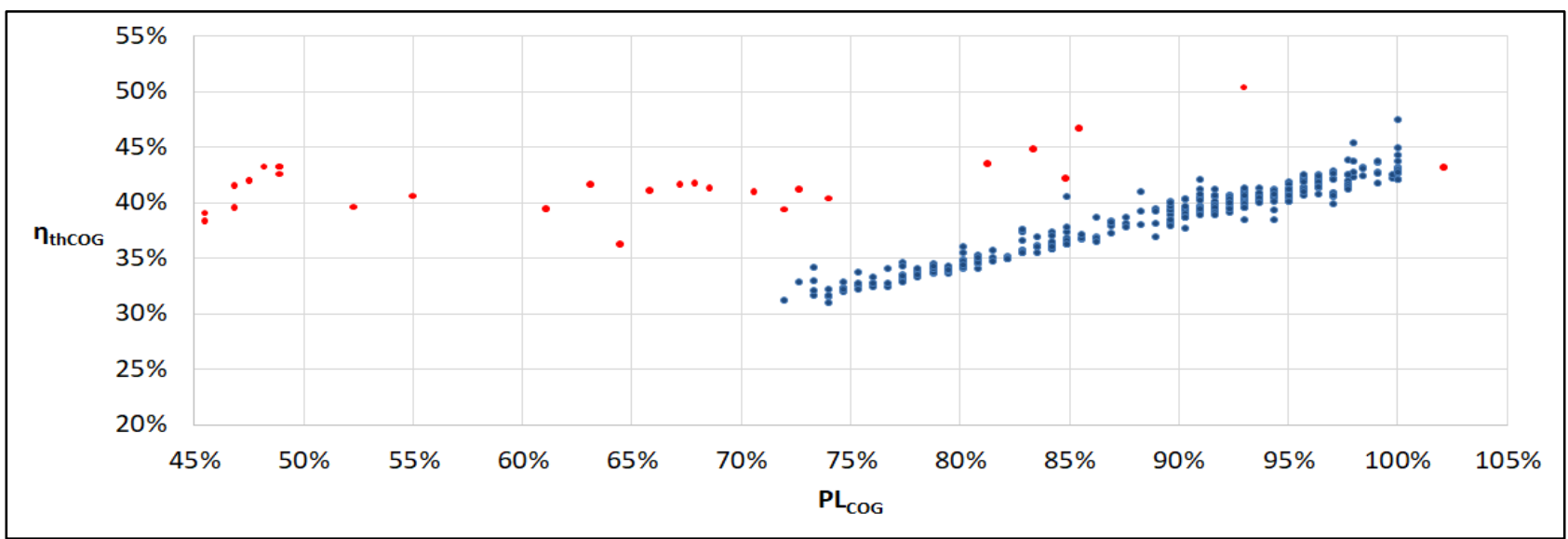


a. - thermal outliers - abnormal operation mode, - optimal values - normal operation mode.

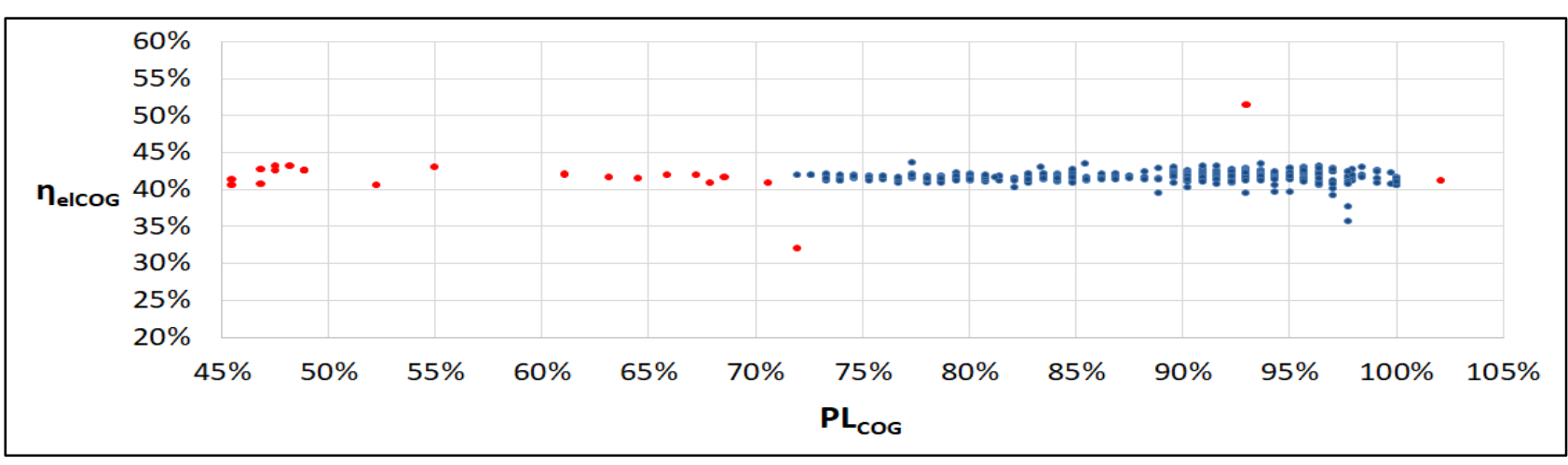

b. $\bullet$ electrical outliers - abnormal operation mode, • optimal values - normal operation mode.

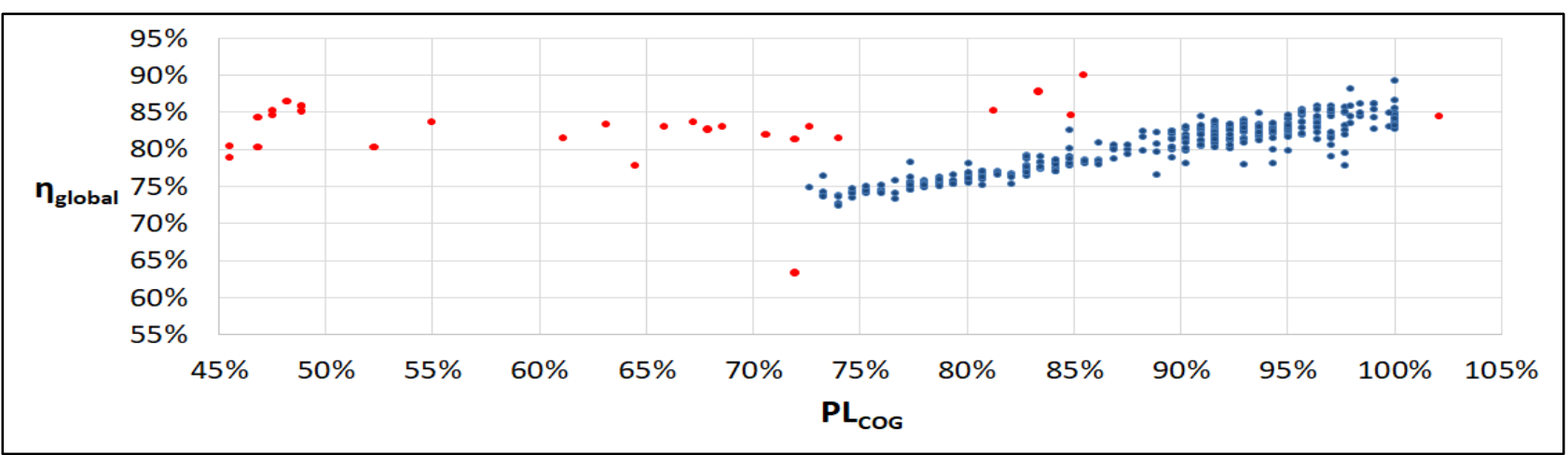

c. - global outliers - abnormal operation mode, - optimal values - normal operation mode.

Fig. 6. Variation of modelled efficiency as a function of the partial load: a. Thermal efficiency, b. Electrical efficiency, c. Global efficiency.

Based on the primary visual analysis, the variation of the modelled global (thermal + electric) efficiency of the cogeneration plant, exhibits an increasing variation with the partial operation load of the engines assembly, $\mathrm{PL}_{\mathrm{COG}}$, Fig. 6, c.

Similar to the pattern of the modelled thermal efficiency, a concentration of cloud of points with a obvious trendline between $72 \%$ and $100 \%$ PL was observed. At the same partial operating load, obviously, several global efficiency values are recorded on different days with very small differences between them (vertically close points). At the same PL, the daily global modelled efficiency returns values that can vary to a maximum of 5 percent.

From the diagram of the normal distribution of the global modelled efficiency, the points that appeared dispersed (the red points) called 'global outliers values' will be removed. The outliers were mainly values recorded during the days when one of engines did not work the whole day or during the maintenance periods. Also will be removed the one day wrong recording data (more than 100\% global efficiency).

The graph of the remaining thermal efficiency values was plotted, Fig. 7. The regression line makes an 23.42 degrees angle with the horizontal, having a slope of $43.32 \%$. Equation (1) expresses the variation of the modelled thermal efficiency after the elimination of the thermal outliers values.

$$
\eta_{\text {thCOG }}^{2 E}=0.4332 \cdot P L_{C O G}+0.0015
$$

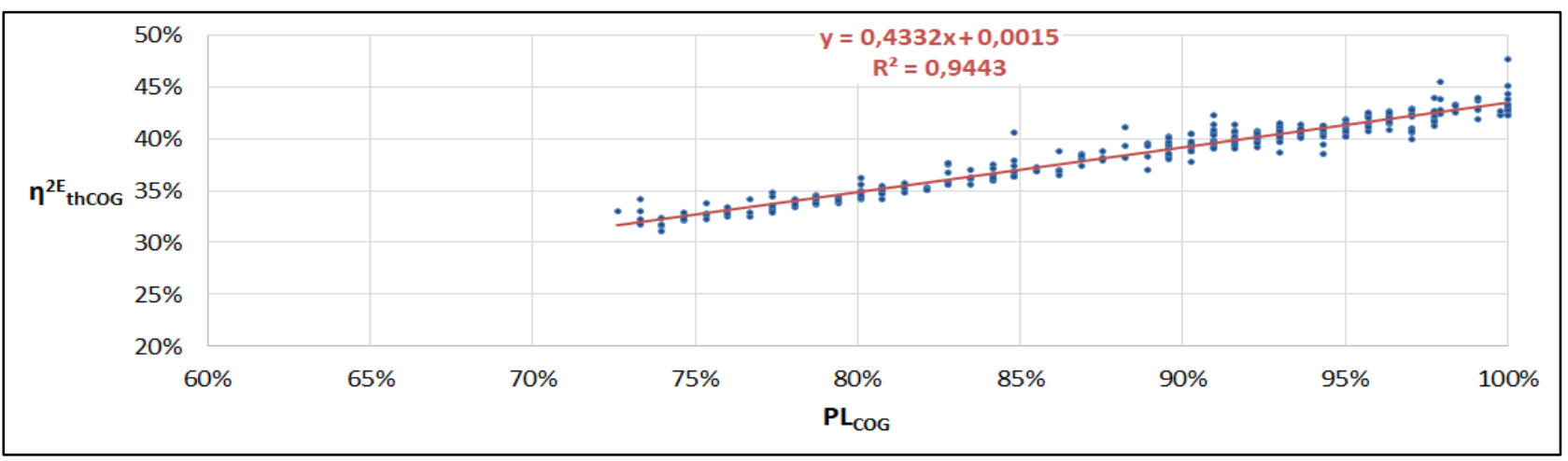


Fig. 7. Variation of modelled thermal efficiency without 'thermal outliers values' with partial load - normal operation mode.

The coefficient of determination $\mathrm{R}^{2}=0,9443$ shows that in this case the values of the independent variable, $\mathrm{PL}_{\mathrm{COG}}$, determine in a large percentage of $94,43 \%$ the values of the modelled thermal efficiency - the dependent variable.

Similarly, the variations of the modelled electrical efficiency with the PL after the removal of the 'electrical outliers values' were processed and analysed, Fig. 8. The modelled global efficiency after the elimination of 'global outliers values' is represented in the Fig. 9. Equations (2), (3) express mathematically the variation of the modelled electrical and global efficiency, without outliers values, with PL.

$$
\begin{aligned}
& \eta_{\text {elCOG }}^{2 E}=0.0054 \cdot P L_{C O G}+0.4126 \\
& \eta_{\text {global }}^{2 E}=0,4372 \cdot P L_{C O G}+0,4152
\end{aligned}
$$

The $0.54 \%$ slope of the regression line is observed in the variation of the modelled electrical efficiency. We can say that, even in the case of the elimination of the outliers values from graph of the modelled electrical efficiency, the PL has an insignificant influence. The ANOVA analysis on the two values ranges, the unbalanced model of electrical efficiency and the partial load, reveals a ' $\mathrm{p}$ ' value of significance threshold higher than $0.05(\mathrm{p}=$ 0.4494), which leads to the assumption that the two value ranges are not related, assuming the null hypothesis is true.

Analyzing the variance of the real efficiency in relation to two variables: the PL and the modelled global efficiency, the goal was to find a multiple regression equation (4) that mathematically describes how the real efficiency $\left(\eta_{\mathrm{BDB}}\right)$ depends on the partial load (PL) and on the modelled global efficiency $\left(\eta_{\text {global }}\right)$. The $3 \mathrm{~d}$ chart was created, Fig. 10.

$$
\begin{aligned}
& \eta_{B D B}=5,47131 \cdot 10^{-17} \cdot P L+0,940055947 \\
& \cdot \eta_{\text {global }}+1,55431 \cdot 10^{-15}
\end{aligned}
$$

An ANOVA analysis showed a poor significance of the partial load coefficient, the ' $\mathrm{p}$ ' value of significance threshold greater than $0.05(\mathrm{p}=0.4117)$. In the regression model described by equation (7) we can not exclude the possibility of the null coefficient of partial load. This is a better understanding of the tabular values since January $1^{\text {st }} 2012$ to January $14^{\text {th }} 2012$, when we have virtually the same efficiency $(80.22 \%-80.28 \%)$ for totally different PL values $(47.50 \%$ and $95.68 \%$, non-functional M2). It can be argued that the variable PL of the two-engine assembly, as considered, does not have a decisive significance in the multiple regression model created in comparison with the modelled global efficiency output. The coefficient of the modelled global efficiency's variable and the intercept have values of very good significance, $\mathrm{p}<0.05$. Less than $1 \%$ of the modelled global efficiency variables are positioned outside the confidence interval $(95 \%)$.

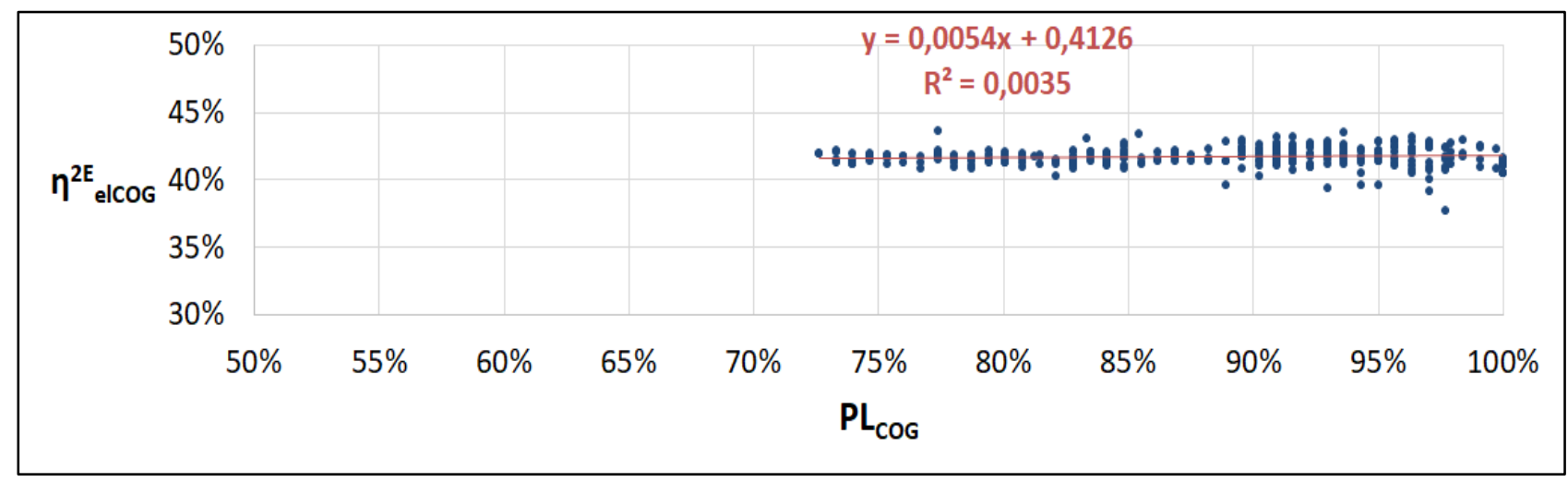

Fig. 8. Variation of modelled electrical efficiency without 'electrical outliers values' with partial load - normal operation mode.

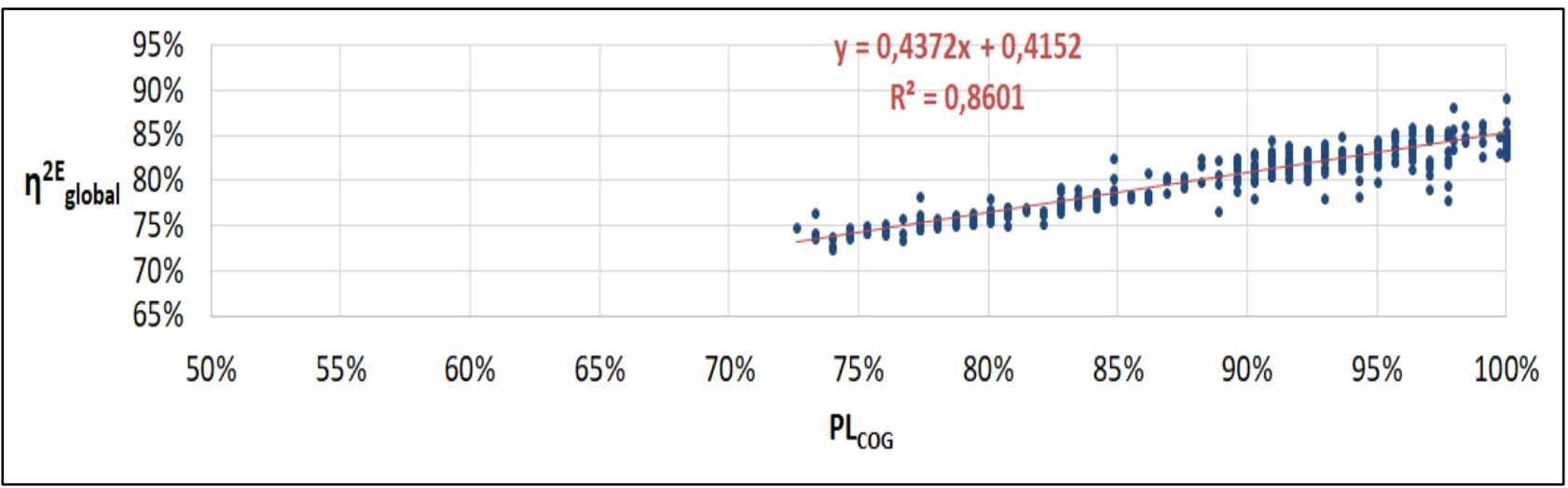


Fig. 9. Variation of modelled global efficiency without 'global outliers values' with partial load - normal operation mode.

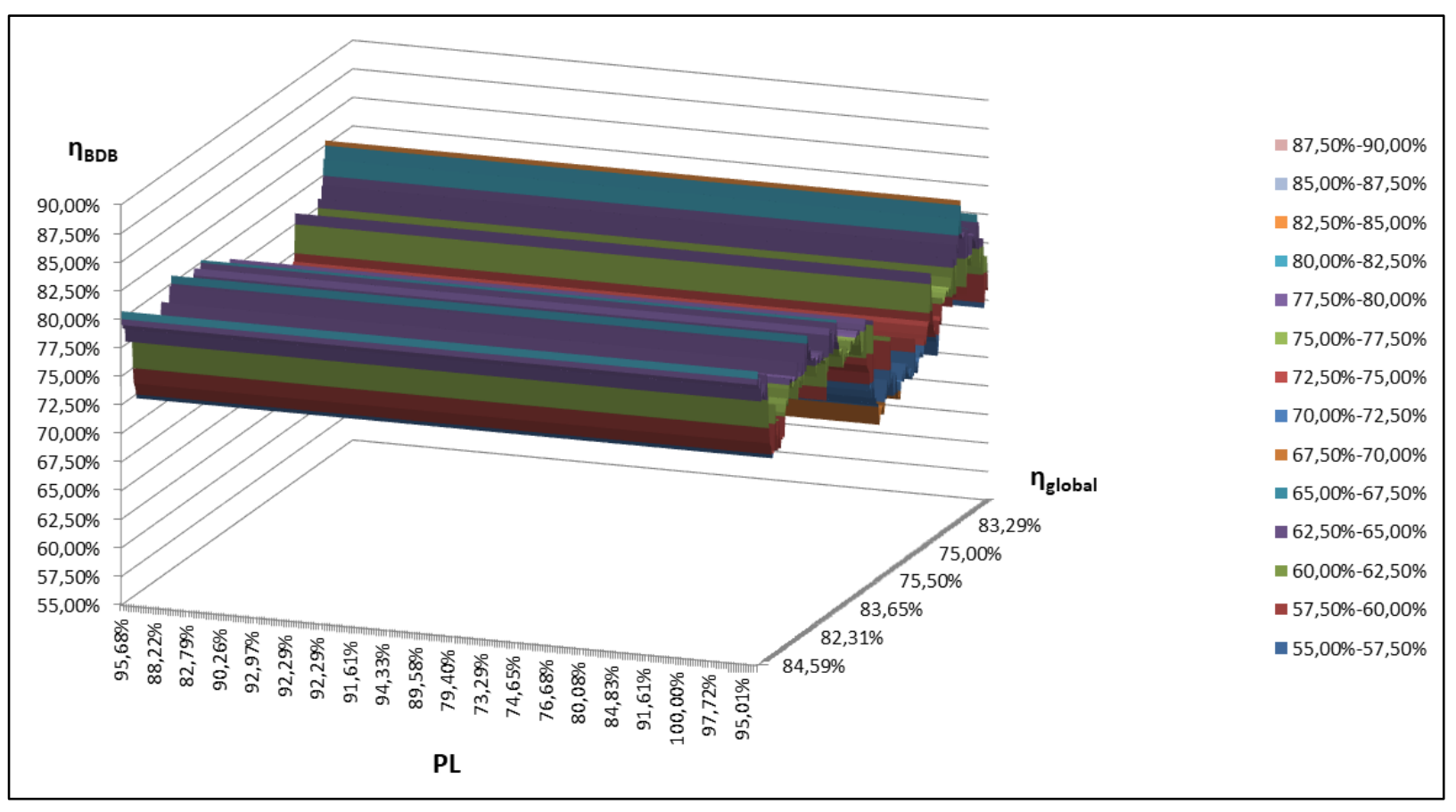

Fig. 10. Variation of real efficiency with modelled global efficiency and with partial load.

\section{Conclusions}

The paper presents a mathematical model of calculation of daily global efficiency in a cogeneration plant with two reciprocating internal combustion engines. Previously were obtained equations of interdependence between the partial load of the thermal engines assembly and the modelled thermal, electrical and global efficiency (calculated with mentioned formulas from this introduction). We obtained the equation of variation of the real efficiency of CHP plant (the efficiency from the database) with the partial load and the equation of variation of the real efficiency of CHP plant (the efficiency from the database) with the modelled (calculated) efficiency. The values of the efficiency from the predictive model strongly determine the real efficiency values from the database. The processing of the database information has occasionally led to finding and correcting a wrong recording data. The behaviour of the CHP plant has been observed by removing of the dispersed values outside (the outliers values). The variation trend of thermal and global efficiency increases with increasing of PL. The electrical efficiency does not depend on PL variation. The obtained regression equations were statistically analysed and conclusions were drawn on the meanings of terms, variables and coefficients. These equations provide the method to adjust the efficiency calculated according to the mentioned formulas so that the final result to be as accurate as possible to the real conditions obtained in the operation of the system.
We would like to thank to Prof. Rodica Frunzulica and to Prof. Florin Baltaretu for their help and support for this research.

\section{References}

1. University of Dundee under co-ordination of Dr. B. Ramsay, Educogen, The European Educational Tool on Cogeneration, Second Edition, 8 (2001)

http://citeseerx.ist.psu.edu/viewdoc/download?doi= 10.1.1.618.8470\&rep $=$ rep $1 \&$ type $=$ pdf

2. G. Mărcuş, V. Iordache, R. Frunzulică, F. Iordache, RRIC, Efficiency analysis of a CHP plant, based on reciprocating engines as prime movers and a hot water boiler as peak source, 9, No. 3, 278 (2018) http://rric.ro/revista.php?id=25

3. S. Sanaye, M. A. Meybodi, S. Shokrollahi, Selecting the prime movers and nominal powers in combined heat and power systems, Elsevier Ltd., Applied Thermal Engineering 28 (2008) https://doi.org/10.1016/j.applthermaleng.2007.08.0 $\underline{03}$

4. ASHRE, ASHRAE Handbook - Heating, Ventilating, and Air-Conditioning Systems and Equipment, I-P Edition, (2008) https://www.ashrae.org/technical-resources/ashraehandbook

5. SR EN 15316-4-4, Energy performance of buildings - Method for calculation of system energy requirements and system efficiencies, Part 4-4, (2017)

6. SR CEN/TR 15316-6-7, Energy performance of buildings - Method for calculation of system 
energy requirements and system efficiencies, Part 6-7,(2017) 